\title{
Four Leg Voltage Source Converter based Dynamic Voltage Restorer for Power Quality Improvement in Distribution Networks
}

\author{
S.Leela \\ Research Scholar \\ Bharath University \\ Chennai, Tamilnadu, \\ India.
}

\author{
S.S. Dash \\ Professor and Head \\ SRM University \\ Chennai, Tamilnadu, \\ India.
}

\begin{abstract}
This paper deals with digital simulation and control of four leg voltage source converter based Dynamic Voltage Restorer(DVR). The control of DVR that injects a voltage in series with a distribution feeder is presented. DVR is a power electronic controller that can protect sensitive loads from disturbances in supply system. It is observed that DVR can regulate the voltage at the load during an imbalance in the three phase system voltage. It eliminates the presence of zero sequence components in unbalanced system to make the system balanced. Circuit model is developed and the same is used for simulation studies.
\end{abstract}

\section{Keywords}

Dynamic Voltage Restorer, FACTS, Four- Leg Voltage Source Converter, MATLAB, PI Control, Simulink

\section{INTRODUCTION}

Flexible AC Transmission Systems (FACTS) technologies allow for improved transmission system operation with minimal infrastructure investment, environmental impact and implementation time compared to the construction of new transmission lines. FACTS technologies provide advanced solutions as cost effective alternative to new transmission line construction. FACTS provide the needed corrections of transmission functions in order to efficiently utilize existing transmission systems and therefore, minimize the gap between the stability and the thermal level.

The voltage source converter based FACTS controllers which includes Static Synchronous Compensator(STATCOM), the Static Synchronous Series Compensator (SSSC) and the Unified Power Flow Controller (UPFC) facilitates flexible power flow control, transient stability and power system oscillation damping enhancement. The UPFC provides control of both real and reactive power. At a substation, solution for the problem of compensating a number of transmission line is provided by Interline Power Flow Controller (IPFC). DVR is a series connected device whose function is to protect a sensitive industrial load from voltage sags [1].

This paper extends the concept of dynamic voltage restorer further to tightly regulate the load voltage. It can also perform the primary functions of the restorer, i.e., to protect the load from temporary voltage interruption, sag/swell etc. This device is called a dynamic voltage regulator (DVR). For the control operation of DVR we stipulate that real power supplied by the device in steady state is zero. Based on this stipulation, the references of the voltages that are to be injected in series are generated. This requires online extraction of the fundamental positive sequence based on the sampled values. Once the reference voltages are obtained, they are tracked by the VSC's realizing the DVR.

A new approach to load balancing and power factor correction is given by Ghosh [2]. The DVR is used in distribution systems for mitigating the various power quality problems [3-8]. The actual implementation of the DVR using inverters raises additional issues of switch frequency injection. To eliminate these, two different filter structures are employed. The proposed DVR is validated through digital computer simulation studies.

The modeling of facts and custom power devices is developed [9-11]. The fuzzy logic control and PI control techniques employed in a four leg VSC based DVR is compared and validated [12]. The performance of VSC based shunt and series compensators used for load voltage control is compared [13].

\section{DVR CHARACTERISTICS}

In this section we shall present the fundamental, positivesequence, steady state analysis of a DVR connected power system. The voltage regulation scheme is shown in Figure 1. This consists the following:

- DVR: represented by voltage sources $\mathrm{V}_{\mathrm{fa}}, \mathrm{V}_{\mathrm{fb}}$ and $\mathrm{V}_{\mathrm{fc}}$

- Supply voltage: represented by sources $\mathrm{V}_{\mathrm{sa}}, \mathrm{V}_{\mathrm{sb}}$ and $\mathrm{V}_{\mathrm{sc}}$

The DVR is connected between a terminal bus on the left and a load bus on the right. The voltage sources are connected to the DVR terminals by a feeder with an impedance of $\mathrm{R}+\mathrm{jX}$. We shall assume that the loads are balanced and the load impedance is given by $Z_{1}=R_{1}+j X_{l}$. It is to be noted that the phase angle $\Phi_{1}$ between the load terminal $V_{1}$ and the line current $i_{S}$ depends on the load impedance and is independent of the line impedance or the DVR voltage.

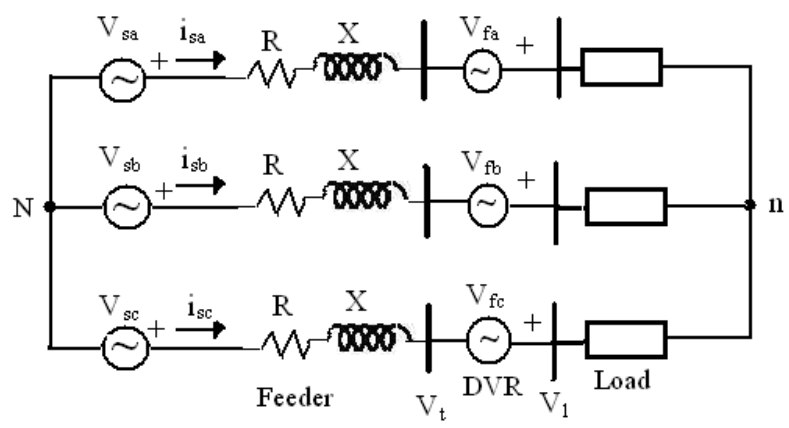

Fig 1: Schematic of DVR connected to power system 
The objective of the discussion presented below is to regulate the magnitude of the load voltage equal to that of the source voltage through DVR voltage injection. Further we stipulate the following condition on the DVR:

- $\quad$ The DVR does not supply any real power in the steady state. This implies that the phase angle difference between DVR voltage phasor and line current phasor must be $\Pi / 2$ in the steady state.

Let us assume that the load current lags the load voltage. To draw a phasor diagram of the steady state operation, we assume that the load voltage is fixed at $\mathrm{V}$ per unit and the source voltage is allowed to vary. Since the primary target is to make the magnitudes of $V_{1}$ and $V s$ equal, the locus of desirable $V_{s}$ is the $\operatorname{arc} \mathrm{NB}$ as shown in Figure 2.

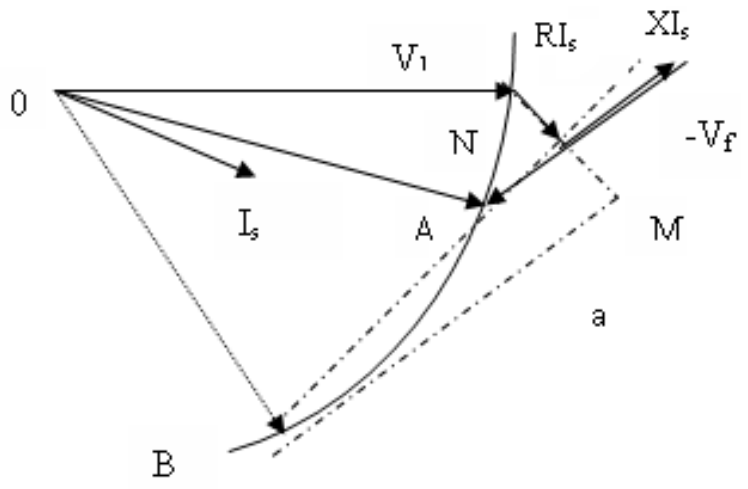

Fig 2: Phasor diagram showing multiple solutions

To make the magnitude of the load voltage equal to that of the source voltage, the $\mathrm{RI}_{\mathrm{s}}$ drop must be less than NM. If the drop is less than this limiting value, the DVR must compensate the entire reactive drop in the feeder and provide additional injection such that the source voltage becomes $\mathrm{V}$ per unit. It can be seen from Figure 2 that there are two possible intersection points with the arc- one at $\mathrm{A}$ and the other at $\mathrm{B}$. This implies that two possible values of DVR voltage and can be obtained for each feeder drop. For the first value, the source voltage will be along OA, while for the other value, it will along OB. It is needless to say that the best choice is the A intersection requiring much smaller voltage injection from the DVR.

Example 1: In this example, we illustrate the procedure for the steady-state computation of DVR voltage. Let the feeder impedance be $0.5+\mathrm{j} 0.3$ per unit, while the load impedance be $2.5+\mathrm{j} 2$ per unit. We now connect a DVR aiming to regulate the load voltage to 1.0 per unit. Let us assume that $\mathrm{rms}$ load voltage is given by $\vec{V}_{l}=1 \angle 0^{0}$ per unit. The line current is then

$$
I_{S}=\frac{1 \angle 0^{0}}{R_{l}+j X_{l}}=0.3123 \angle-38.66^{0} \mathrm{p} \mathrm{u}
$$

For zero DVR power, its voltage must be in quadrature to the line current. We then have

$$
\vec{V}_{f}=\left|\vec{V}_{f}\right| e^{j \angle\left(\vec{I}_{s}+90\right)}=\left|\vec{V}_{f}\right| \angle 51.34^{0}=\left|\vec{V}_{f}\right|\left(a_{1}+j b_{1}\right)
$$

(1)

where $\mathrm{a}_{1}+\mathrm{jb} \mathrm{b}_{1}$ is a unit phasor at $90^{0}$ to $\vec{I}_{s}$. Again from Figure 1 we get

$$
\vec{V}_{s}+\vec{V}_{f}=\vec{V}_{l}+(R+j X) \vec{I}_{s}=\vec{V}_{l}+a_{2}+j b_{2}
$$

where $a_{2}+j b_{2}$ represents the feeder drop.

Subsituting (1) in (2) and rearranging we get

$$
\vec{V}_{s}=\vec{V}_{l}+a_{2}+j b_{2}-\left|\vec{V}_{f}\right|\left(a_{1}+j b_{1}\right)
$$

The following quadratic equation is then obtained from the magnitude condition of (3)

$$
\begin{aligned}
& \left|\vec{V}_{f}\right|^{2}-2\left\{a_{1}\left(\left|\vec{V}_{1}\right|+a_{2}\right)+b_{1} b_{2}\right\}\left|\vec{V}_{f}\right| \\
& +\left(\left|\vec{V}_{l}\right|+a_{2}\right)^{2}+b_{2}{ }^{2}-\left|\vec{V}_{s}\right|^{2}=0
\end{aligned}
$$

Let us assume that the magnitude of the source voltage is 1.0 per unit. Then solving the above equation we get

$$
\left|\vec{V}_{f}\right|=0.1137 \& 1.3231
$$

These two values of the magnitude of the injected voltage correspond to two operating points (A and B) in Figure 2. We shall obviously choose the lower of the two values.

\section{FOUR LEG VOLTAGE SOURCE CONVERTER BASED DVR}

The distribution systems are inherently unbalanced. Due to load fluctuation, difficulty arised in controlling the distribution voltages within limits. Also if the phases are unequally loaded, it results in the production of negative and zero sequence currents. The negative sequence results in overheating in machines, saturation of transformer and ripples in rectifier. The zero sequence components not only results in excessive power loss in neutral lines but also affects protection. DVR is a voltage-source converter connected in series with the $\mathrm{AC}$ network through an interfacing transformer. It employs a PI controller. The PI controller is shown in Figure 3. The desired output is compared with the actual output and an error signal is generated. This is given to the Pulse Width Modulation for controlling the switching pattern. It also helps mitigate the amount of harmonics. The PWM generation of pulses is shown in the Figure 4. The switching pulses to the four leg inverter is shown in Figure 5. 


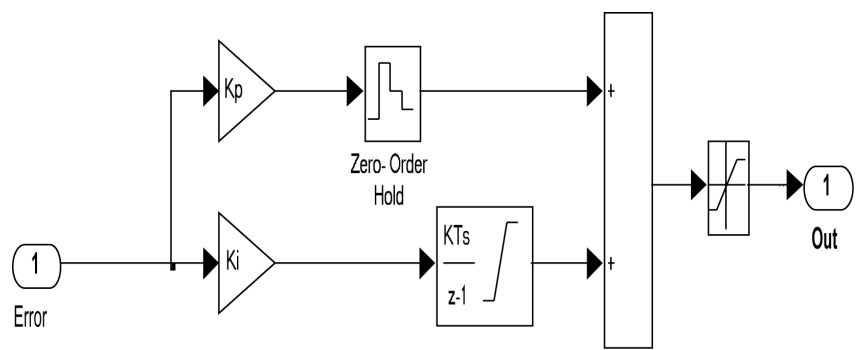

Fig 3: PI Controller

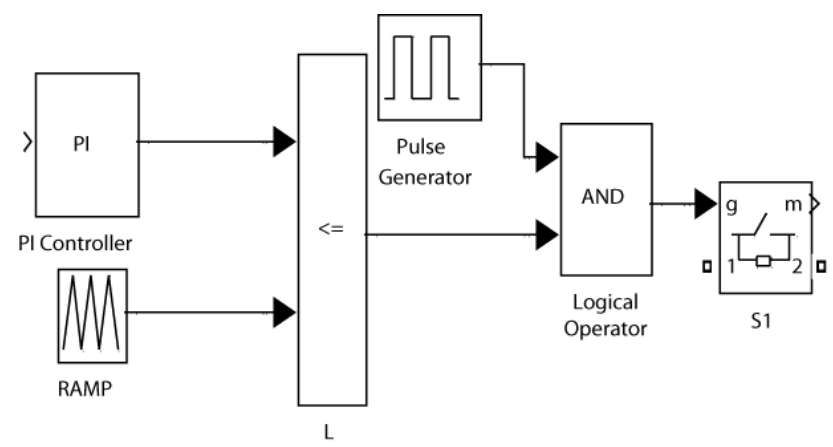

Fig 4: PWM generation of pulses

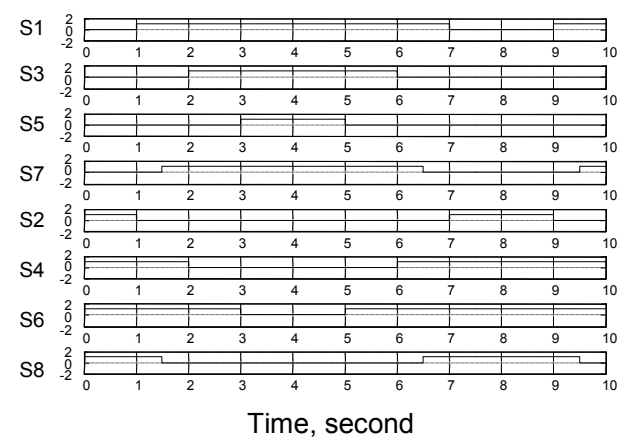

Fig 5: Switching pulses to the four leg Inverter

The four leg Voltage Source Converter based DVR is shown in Figure 6. The four leg inverter is connected to the secondary side of the transformer. The fourth leg generates the compensating signal to balance the system. It minimizes the switching losses and produces a high quality sinusoidal voltage waveform with minimum filtering requirements. It can compensate for unbalanced load currents containing $\mathrm{dc}$ components in a three-phase four-wire system.

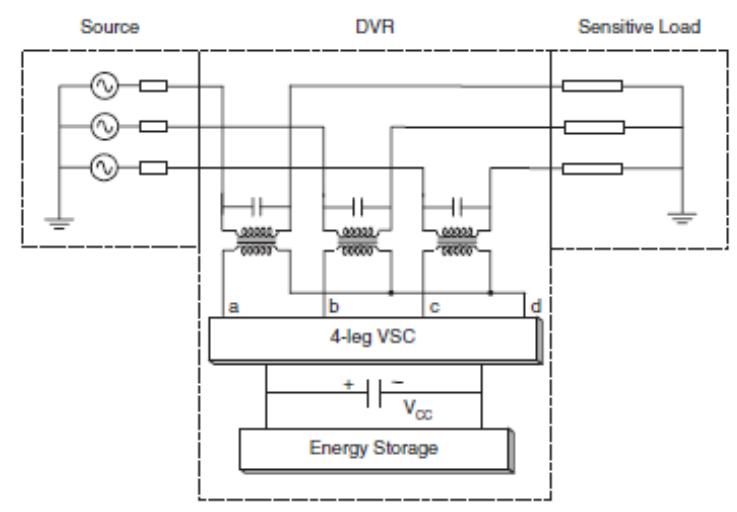

Fig 6: Four leg VSC based DVR

\section{SIMULATION RESULTS}

A three phase four leg Dynamic Voltage Restorer simulated in normal balanced condition is shown in the Figure 7a. Its input voltage is presented in Figure $7 \mathrm{~b}$. The output voltage waveform under balanced condition is shown in Figure 7c.

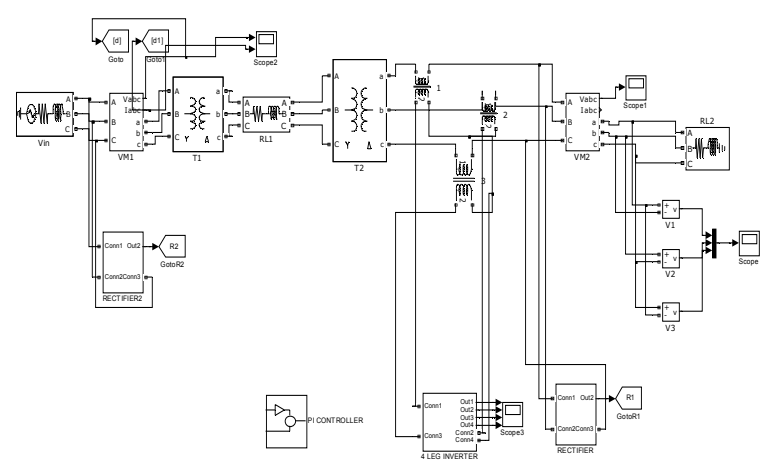

Fig 7a: Four leg DVR in balanced condition

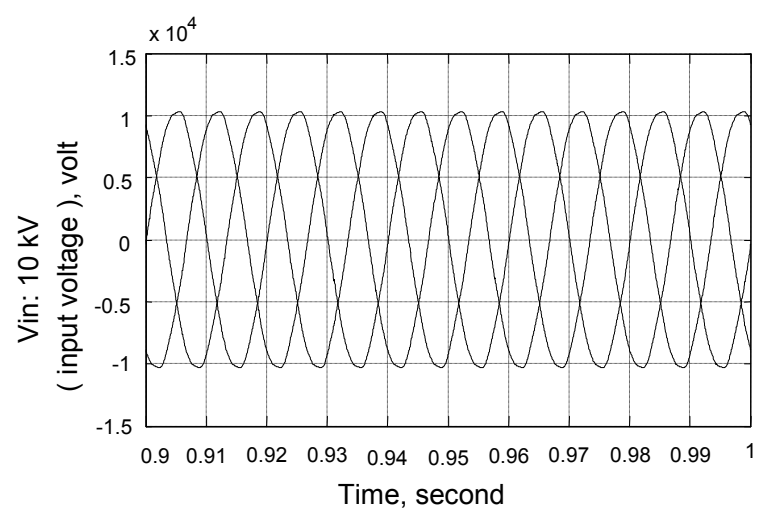

Fig 7b: Input voltage waveform in balanced condition 


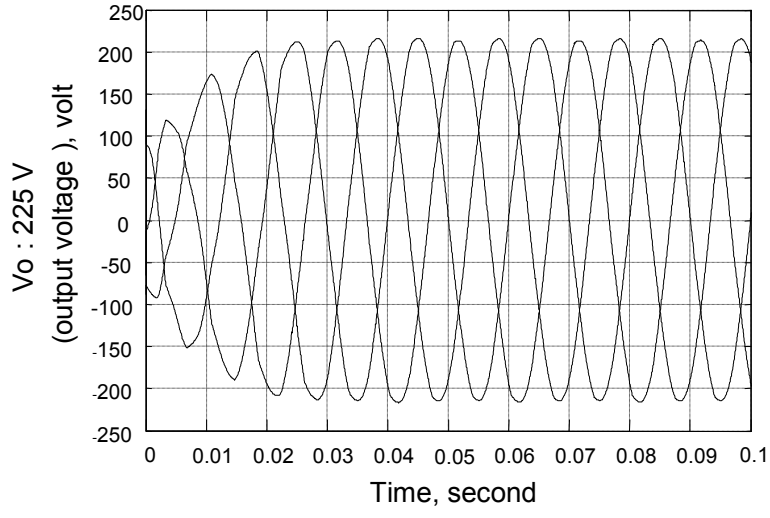

Fig 7c: Output voltage waveform in balanced condition

The four leg Dynamic Voltage Restorer is simulated under a three phase fault condition. A fault occurs between the time intervals of 0.2 to 0.4 seconds as shown in Figure 8a. The fault is recovered by series compensation through DVR. The recovery of the fault is dynamic and it is shown in Figure $8 \mathrm{~b}$.

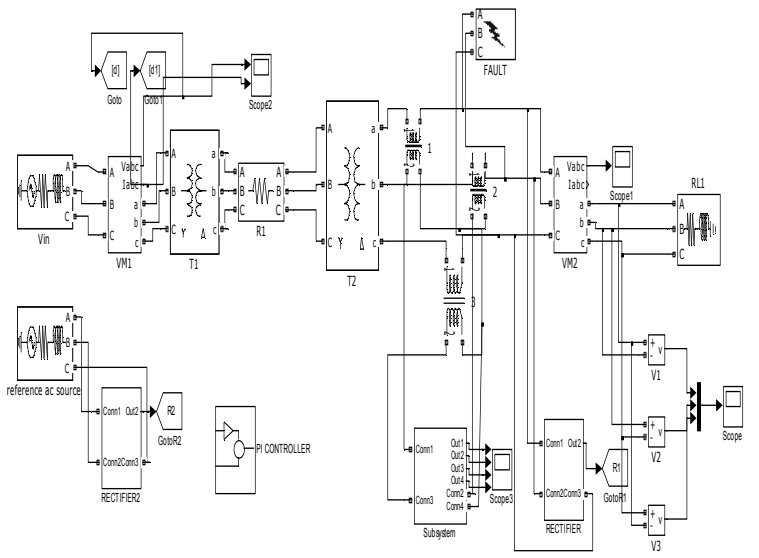

Fig 8a: Four leg DVR with fault

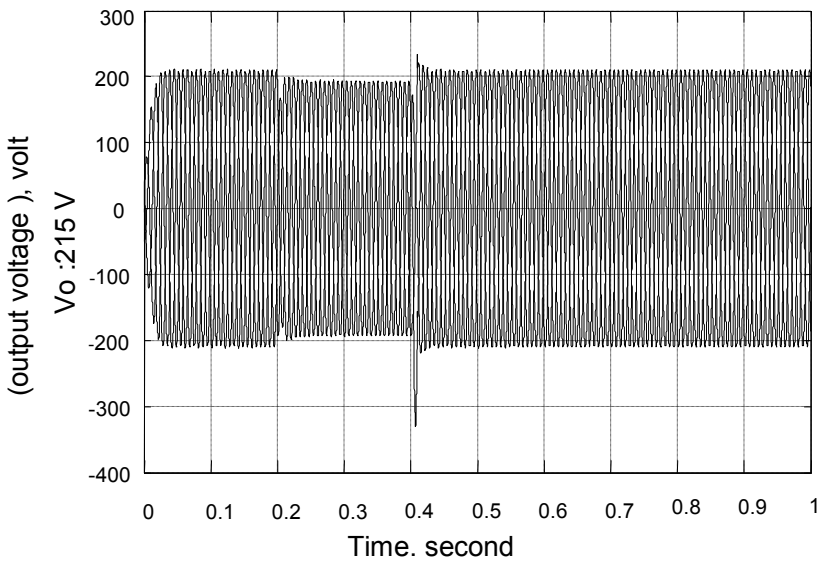

Fig 8b: Output voltage waveform under fault condition
When the four leg sytem is under any imbalance, such as imbalance voltage in the source side, as shown in Figure 9a, the Dynamic Voltage Restorer, restores the balance in the system through the fourth leg of the converter as shown in Figure $9 b$.

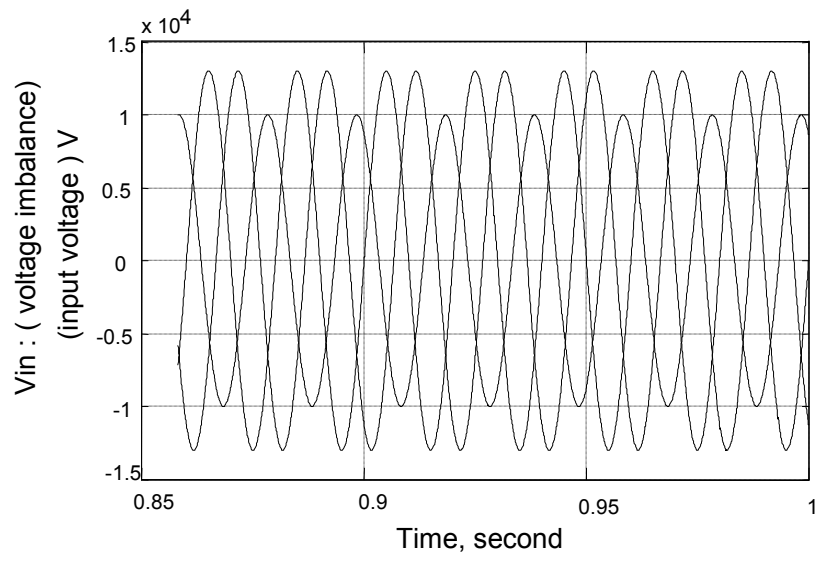

Fig 9a: Unbalanced input voltage waveform

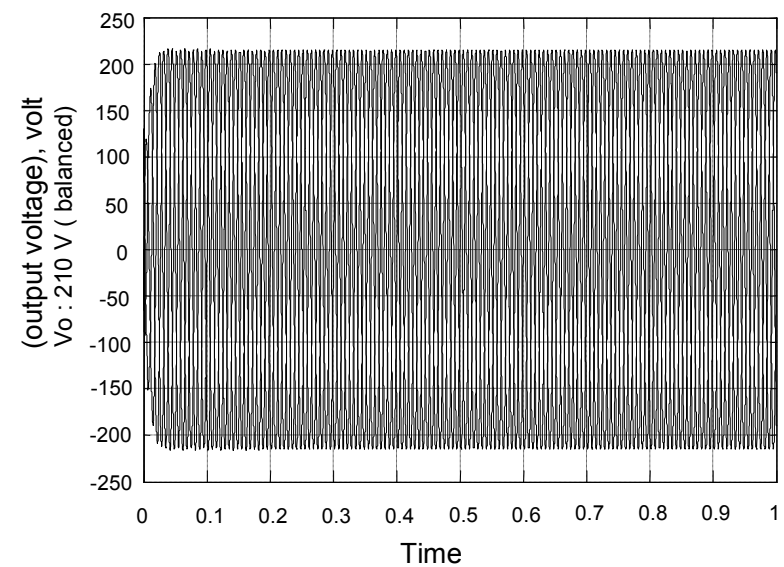

Fig 9b: Balanced output voltage waveform

\section{CONCLUSION}

This paper presents circuit modelling and simulation of four leg voltage source converter based DVR system. This paper demonstrates the capability of DVR to improve the voltage quality. The performance of the four leg voltage source converter based DVR for unbalanced systems is simulated and the results are presented. The DVR can regulate the voltage at the load during an imbalance in the three phase system voltage. It eliminates the presence of zero sequence components in unbalanced system to make the system balanced. The simulation results are in line with the predictions.

\section{REFERENCES}

[1] Alexander Kara, Peter Dahler, David Amhof, Horst Grunning, 'Power Supply Quality Improvement With A Dynamic Voltage Restorer', Conference ProceedingsIEEE Applied Power Electronics Conference and Exposition-APEC, Vol.2, pp.986-993, 1998. 
[2] A. Ghosh and A. Joshi, 'A new approach to load balancing and power factor correction in power distribution system', IEEE Trans. on Power Delivery, Vol.15, No.1, pp.417-422, 2000.

[3] P.T. Nguyen and Tapan. K. Saha, 'Dynamic Voltage Restorer Against Balanced and Unbalanced Voltage Sags: Modelling and Simulation', IEEE, pp.1-6, 2004.

[4] Praveen, P. Bishnu, Muni S. Venkateshwarlu and H.V. Makthal, 'Review Of Dynamic Voltage Restorer For Power Quality Improvement', The $30^{\text {th }}$ Annual Conference of the IEEE Industrial Electronics Society(IECON), pp. 749-754, 2004.

[5] Agileswari,K.Ramasamy,RenganKrishnanIyer,Dr.Vigna,K. Ramachandramurthy and Dr. K.N. Mukerjee, 'Dynamic Voltage Restorer for voltage sag compensation', IEEE PEDS, pp.1289-1294, 2005.

[6] P. Boonchiam and N. Mithulananthan, 'Dynamic Control Strategy In Medium Voltage DVR For Mitigating Voltage Sags/Swells', International Conference on Power System Technology, 2006.

[7] Chellali Benachaiba and Brahim Ferdi, 'Voltage Quality Improvement Using DVR', Electrical Power Quality and Utilization, Vol.14, No.1, pp.39-45, 2008.

[8] F.A.L. Jowder, 'Design and Analysis of Dynamic Voltage Restorer for Deep Voltage Sag and Harmonic Compensation', IET Generation, Transmission and Distribution, Vol.3, No.6, pp. 547-560, 2009.

[9] Ashwin Kumar Sahoo and T.Thyagarajan, 'Modeling of facts and custom power devices in distribution network to improve power quality', Third International Conference on Power Systems, pp.1-7, 2009.

[10] M. Arun Bhaskar, Dr. S.S. Dash, C. Subramani, M. Jagdeesh Kumar, P.R. Giresh and M. Varun Kumar,
'Voltage Quality Improvement Using DVR', International Conference on Recent Trends in Information, Telecommunication and Computing, pp.378-380, 2010.

[11] R.A. Kantaria, S.K. Joshi and K.R. Siddhapura, 'A Novel Technique for Mitigation of Voltage Sag/Swell by Dynamic Voltage Restorer (DVR)', IEEE, pp.1-4, 2010.

[12] B.A. Priyanka and K. Vijayakumar 'Four Leg Voltage Source Converter Based Dynamic Voltage restorer', International Journal of Technology and Engineering System, Vol.2, No.2, pp.138-142, 2011.

[13] Rajesh Gupta, Arindam Ghosh and Avinash Joshi, 'Performance Comparison of VSC-Based Shunt and Series Compensators Used for Load Voltage Control in Distribution Systems', IEEE Transactions on Power Delivery, Vol.26, No.1, pp.268-278, 2011.

\section{AUTHORS PROFILE}

S. Leela has obtained her BE degree from Bharathidasan University in the year 1990 and ME degree from Sathyabama Institute of Science and Technology in the year 2006. Presently she is a research scholar at Bharath University, Chennai, Tamilnadu, India.. She is presently working as Assistant Professor in Sastra University, Tanjore District, India. Her interests are in the area of power quality improvement.

Dr. S.S. Dash is a Professor of Electrical Engineering at SRM University, Chennai since 2007. In 2006 he has obtained his Ph.D degree from Anna University, Chennai. He has held various positions in C.V. Raman College Of Engg., Orissa, Anna University and SSN College Of Engg., Chennai.. His interests are in the areas of Power Electronics and Power Quality Improvement 